\title{
Changes in biogenic amine concentrations in meat of eviscerated pheasants (Phasianus colchicus) during storage at $7^{\circ} \mathrm{C}$
}

\author{
Zdeňka Hutařová ${ }^{1}$, Vladimír Večerek ${ }^{1}$, Petr Maršálek ${ }^{1}$, Iva Steinhauserová2 ${ }^{2}$ Gabriela Bořilová2 \\ ${ }^{1}$ University of Veterinary and Pharmaceutical Sciences Brno, Faculty of Veterinary Hygiene and Technology, \\ Department of Veterinary Public Health and Toxicology, ${ }^{2}$ Department of Meat Hygiene and Technology, Brno, \\ Czech Republic
}

Received August 1, 2012

Accepted March 19, 2013

\begin{abstract}
In our study, we tested biogenic amine concentrations in 20 eviscerated pheasants killed by pithing (the slaughtering technique in which the spinal cord of the animals is severed and their brain is destroyed) and stored at $7{ }^{\circ} \mathrm{C}$ for 21 days. Biogenic amine concentrations in breast and thigh muscles were analysed by reverse phase liquid chromatography. In the thigh muscle, the highest increases during the storage time were found in cadaverine $(20.17 \pm 18.66 \mathrm{mg} / \mathrm{kg})$, putrescine $(4.39 \pm 4.17 \mathrm{mg} / \mathrm{kg})$ and tyramine $(15.20 \pm 16.88 \mathrm{mg} / \mathrm{kg})$ concentrations. Changes of biogenic amine concentrations in the breast muscle were minimal during the whole storage time. The concentration of biogenic amines in meat is associated with the presence of contaminating microorganisms. For that reason, biogenic amines are often used as markers of meat spoilage in various livestock species. Based on our results, the biogenic amines cadaverine, putrescine and tyramine may be considered the main indicators of hygienic quality of pheasant meat. We can recommend storing pithed pheasants treated by evisceration no longer than for seven days at $7^{\circ} \mathrm{C}$. After that period, biogenic amine concentrations in meat begin to change. The main significance of this study lies in the extension of the lack information about the content of biogenic amines in the meat of eviscerated pithed pheasant and also about changes of their concentrations during the course of storage.
\end{abstract}

Game meat, hygienic quality, putrescine, cadaverine, tyramine

Biogenic amines are organic compounds derived from amino acids. At low concentrations, they are naturally occurring components of foods. Under certain conditions, however, they are produced in greater quantities. The most important conditions influencing biogenic amine production include fresh food quality, storage temperature, the presence of microorganisms with decarboxylase activity, the existence of favourable conditions for microorganism proliferation and the synthesis of their decarboxylase enzyme (Santos 1996; Shalaby 1996; Naila et al. 2010). Biogenic amines as the final products of degradation processes are then used as indicators of food spoilage. From the meat freshness assessment point of view, the most important biogenic amines are cadaverine, putrescine, histamine and tyramine (Hernández-Jover et al. 1997).

The importance of biogenic amines in terms of hygiene lies in their possible negative effects on the human organism (Shalaby 1996; Naila et al. 2010; Standarová et al. 2012). Formation of biogenic amines during meat storage has been investigated in a number of studies. Many of them describe trends in the biogenic amine formation in beef, pork (Yano et al. 1994; Pichner et al. 2000) and poultry meat (Silva and Glória 2002; Balamatsia et al. 2006). There are also studies addressing differences in the rate and intensity of biogenic amine formation between red (beef) and white (poultry) meat (Vinci and Antonelli 2002). Differences in the formation of biogenic amines between breast and thigh muscle in chicken meat were studied by, e.g. Silva and Glória (2002).

There are only few studies where the dynamics and rates of biogenic amine formation in meat of feathered game have been investigated. Paulsen et al. (2008) studied the 
consequences of shotgun wounds and storage conditions on hygienic safety of feathered game. In almost $90 \%$ of samples collected from uneviscerated pheasants (shot or slaughtered) stored at temperatures of $0{ }^{\circ} \mathrm{C}$ or $4{ }^{\circ} \mathrm{C}$ for a maximum period of 14 days, biogenic amine concentrations were below the detection limit. Low biogenic amines concentrations were ascribed to low microbial contamination of the meat of game birds.

Game meat ranks among highly appreciated food. In terms of hygiene, however, it is a food that spoils easily (Standarová et al. 2012). The quality of game meat is largely determined by the handling of game animals after they are killed. Current recommendations suggest that feathered game carcasses should be eviscerated by the removal of organs from the body cavity to ensure hygienic safety of the birds bagged (Winkelmayer et al. 2004). Evisceration shortly after killing, on the other hand, may cause higher bacterial contamination of muscle surfaces (El-Ghareeb et al. 2009). Nowadays, raising pheasants on farms for slaughter and subsequent meat production is becoming more important (Hofbauer et al. 2010).

In our study, we therefore tested concentrations of biogenic amine in the meat of pheasants killed by pithing, eviscerated by removing their organs from the body cavity, and stored at $7{ }^{\circ} \mathrm{C}$ for 21 days.

\section{Materials and Methods}

To monitor biogenic amine concentrations in pheasant meat, we used randomly selected 20 male common pheasants of the mean weight of $1300 \mathrm{~g} \pm 187 \mathrm{~g}$. The pheasant were fed at the Nový Jičín school farm belonging to the University of Veterinary and Pharmaceutical Sciences Brno. The pheasants were killed by pithing (severing their spinal cord and destroying the brain, which causes rapid death of the birds). Pheasant carcasses were handled in accordance with recommendations for hunters' handling and processing of pheasant carcasses, which specify the evisceration of organs from the body cavity. In this procedure, organs of the body cavity are removed through a small opening created by an incision from the cloaca toward the sternum. Eviscerated pheasant carcasses were placed in a cooler standardly used for game meat chilling, and kept there at a controlled temperature of $7^{\circ} \mathrm{C}$. We chose that temperature because people who buy pheasants often hang them outdoors and keep them there at ambient temperature which is often around $7^{\circ} \mathrm{C}$ in November or December.

Samples for biogenic amine determination were taken at weekly intervals (on days 1, 7, 14 and 21 after the birds were sacrificed). On each sampling day, breast and thigh muscle samples were always taken from five pheasants. To ensure the representativeness of the samples, the collected breast and thigh muscles were pureed. From this homogenised material the amount of $0.5 \mathrm{~g}$ was consequently withdrawn for biogenic amines assessment.

One-step extraction using mixtures of trichloracetic acid in water (5\%) followed by clean-up step using $0.45 \mu \mathrm{m}$ syringe filter was employed for sample preparation.

Biogenic amines (putrescine, cadaverine, histamine, spermidine, spermine, tyramine, phenylethylamine and tryptamine) were subsequently separated by reverse phase liquid chromatography using $\mathrm{C}_{18}(2.1 \mathrm{~mm} \times 50 \mathrm{~mm}$, $1.9 \mu \mathrm{m}$; Thermo, San Jose, CA, USA) column and detected by tandem mass spectrometry using a heated electro spray-ionization in positive ion mode. Thermo Scientific UHPLC Accela 1250 system was connected to a Thermo Scientific TSQ Quantum Access MAX Triple Quadrupole Instrument (Thermo, San Jose, CA, USA).

The results were analyzed by Kruskal-Wallis test in the statistical analysis package UNISTAT 5.6. $P$ values $<0.05$ and 0.01 were considered significant and highly significant, respectively.

\section{Results}

Mean concentrations of biogenic amine found in breast muscle samples from eviscerated pheasants stored for 21 days at $7{ }^{\circ} \mathrm{C}$ are shown in Table 1 .

Marked changes in concentrations of the biogenic amine monitored (changes in excess of $0.5 \mathrm{mg} / \mathrm{kg}$ ) in breast muscle of pheasants occurred only in cadaverine (from 0.03 to $3.02 \mathrm{mg} / \mathrm{kg}$ ) and tyramine (from 0.00 to $0.59 \mathrm{mg} / \mathrm{kg}$ ). However, the increase in concentrations of these biogenic amines that occurred during storage was not significant. Changes in putrescine, histamine, phenylethylamine and tryptamine concentrations were minimal (less than $0.5 \mathrm{mg} / \mathrm{kg}$ ). Polyamine spermine was found in high concentrations from the first day of storage. Spermidine was found in rather high concentrations on the first day of storage, and its concentrations did not change much throughout the monitoring. Furthermore, 
Table 1. Biogenic amine concentrations $(\mathrm{mg} / \mathrm{kg})$ in the breast muscle of eviscerated pheasants stored at the temperature of $7^{\circ} \mathrm{C}$.

\begin{tabular}{lcrrr}
\hline Biogenic amines & \multicolumn{4}{c}{ Day of storage } \\
& 1 & 7 & \multicolumn{1}{c}{14} & \multicolumn{1}{c}{21} \\
\hline Putrescine & $0.01 \pm 0.00$ & $0.01 \pm 0.00$ & $0.01 \pm 0.00$ & $0.01 \pm 0.00$ \\
Cadaverine & $0.03 \pm 0.00$ & $0.03 \pm 0.00$ & $0.03 \pm 0.00$ & $3.02 \pm 6.01$ \\
Histamine & $0.03 \pm 0.03$ & $0.01 \pm 0.00$ & $0.01 \pm 0.00$ & $0.08 \pm 0.15$ \\
Spermidine & $1.90 \pm 0.42$ & $1.82 \pm 0.53$ & $1.93 \pm 0.65$ & $2.25 \pm 0.76$ \\
Spermine & $59.40 \pm 11.86$ & $45.39 \pm 3.30$ & $48.61 \pm 2.21$ & $55.70 \pm 2.49$ \\
Tyramine & $0.00 \pm 0.00$ & $0.00 \pm 0.00$ & $0.16 \pm 0.34$ & $0.59 \pm 0.52$ \\
Phenylethylamine & $0.00 \pm 0.00$ & $0.00 \pm 0.00$ & $0.00 \pm 0.00$ & $0.00 \pm 0.00$ \\
Tryptamine & $0.00 \pm 0.00$ & $0.00 \pm 0.00$ & $0.00 \pm 0.00$ & $0.05 \pm 0.10$ \\
\hline
\end{tabular}

Results are given as mean (of the five samples analysed) \pm standard deviation

an increase in biogenic amine concentrations in the pheasant breast muscle occurred mainly after storage day 14; the biogenic amines involved were cadaverine (from 0.03 to $3.02 \mathrm{mg} / \mathrm{kg}$ ) and tyramine (from 0.00 to $0.59 \mathrm{mg} / \mathrm{kg}$ ). The changes in concentrations, however, were not significant.

Mean concentrations of biogenic amine found in the thigh muscle samples from eviscerated pheasants stored for 21 days at $7^{\circ} \mathrm{C}$ are shown in Table 2 .

Table 2. Biogenic amine concentrations $(\mathrm{mg} / \mathrm{kg})$ in the thigh muscle of eviscerated pheasants stored at the temperature of $7^{\circ} \mathrm{C}$.

\begin{tabular}{lcccc}
\hline Biogenic amines & \multicolumn{3}{c}{ Day of storage } & 14 \\
\hline Putrescine & 1 & 7 & $4.28 \pm 1.99$ & 21 \\
Cadaverine & $0.13 \pm 0.22$ & $0.14 \pm 0.15$ & $18.32 \pm 9.50$ & $20.17 \pm 18.66$ \\
Histamine & $0.52 \pm 0.22$ & $0.17 \pm 0.08$ & $0.49 \pm 0.16$ & $0.58 \pm 0.24$ \\
Spermidine & $1.23 \pm 0.24$ & $1.18 \pm 0.19$ & $1.85 \pm 0.36$ & $2.35 \pm 0.47$ \\
Spermine & $35.13 \pm 4.77$ & $27.42 \pm 1.84$ & $32.06 \pm 2.57$ & $36.96 \pm 4.52$ \\
Tyramine & $0.00 \pm 0.00$ & $0.00 \pm 0.00$ & $12.23 \pm 19.22$ & $15.20 \pm 16.88^{*}$ \\
Phenylethylamine & $0.00 \pm 0.00$ & $0.00 \pm 0.00$ & $0.01 \pm 0.02$ & $0.00 \pm 0.00$ \\
Tryptamine & $0.00 \pm 0.00$ & $0.00 \pm 0.00$ & $0.03 \pm 0.06$ & $0.41 \pm 0.79$ \\
\hline
\end{tabular}

Results are given as mean (of the five samples analysed) \pm standard deviation

*Significant increase compared to the biogenic amine concentration assessed on the first storage day

Marked changes in biogenic amine concentrations (changes in excess of $0.5 \mathrm{mg} / \mathrm{kg}$ ) in the thigh muscle of pheasants occurred only in cadaverine (from 0.13 to $20.17 \mathrm{mg} / \mathrm{kg}$ ), tyramine (from 0.00 to $15.20 \mathrm{mg} / \mathrm{kg}$ ) and putrescine (from 2.17 to $4.39 \mathrm{mg} / \mathrm{kg}$ ). The increase in tyramine concentrations during storage was significant $(P<0.05)$. The increase in concentrations of the remaining two biogenic amines (cadaverine and putrescine) during storage was non-significant. An increase in concentration was also recorded for spermidine, but the changes were not as marked as those of the above two biogenic amines. Changes in concentrations of the remaining biogenic amines monitored (histamine, phenylethylamine and tryptamine) were minimal throughout storage (less than $0.5 \mathrm{mg} / \mathrm{kg}$ ). Spermine concentrations were relatively high after day 1 of storage, but no major changes were found on any of the remaining sampling days. Furthermore, changes 
in biogenic amine concentrations in the pheasant thigh muscle occurred after storage day 7. This is particularly true for cadaverine (increase from 0.13 to $18.32 \mathrm{mg} / \mathrm{kg}$ ), tyramine (increase from 0.00 to $12.23 \mathrm{mg} / \mathrm{kg}$ ) and putrescine (increase from 2.17 to $4.28 \mathrm{mg} / \mathrm{kg}$ ). However, none of these changes in concentrations were significant.

Comparison of biogenic amine concentrations between breast muscle (Table 1) and thigh muscle (Table 2) shows clear differences in the intensity and speed of biogenic amine formation, which are apparent mainly after the first week of storage. During storage, thigh muscle concentrations of cadaverine, tyramine and putrescine grow mainly between storage days 7 and 14, i.e. at the time when there are still no major changes in breast muscle. After 14 days of storage, highly significant differences $(P<0.01)$ were observed in cadaverine $(0.03 \mathrm{mg} / \mathrm{kg}$ and $18.32 \mathrm{mg} / \mathrm{kg}$ for breast and thigh muscles, respectively), tyramine $(0.16 \mathrm{mg} / \mathrm{kg}$ and $12.23 \mathrm{mg} / \mathrm{kg}$ for breast and thigh muscles, respectively) and putrescine $(0.01 \mathrm{mg} / \mathrm{kg}$ and $4.28 \mathrm{mg} / \mathrm{kg}$ for breast and thigh muscles, respectively). During storage week three, an increase in biogenic amine concentrations was observed not only in the thigh muscle, but also in the breast muscle. Biogenic amine concentrations found in the thigh muscle at the end of the storage period were markedly higher than biogenic amine concentrations in the breast muscle. After 21 days of storage, a highly significant difference $(P<0.01)$ was found in putrescine (breast muscle concentration $0.01 \mathrm{mg} / \mathrm{kg}$; thigh muscle concentration $4.39 \mathrm{mg} / \mathrm{kg}$ ), and a significant difference $(P<0.05)$ was found in tyramine $(0.59 \mathrm{mg} / \mathrm{kg}$ and $15.20 \mathrm{mg} / \mathrm{kg}$ for breast and thigh muscles, respectively). The relatively high difference in cadaverine concentrations between the breast muscle $(3.02 \mathrm{mg} / \mathrm{kg})$ and the thigh muscle $(20.17$ $\mathrm{mg} / \mathrm{kg}$ ) was non-significant.

\section{Discussion}

It follows from the results obtained in our study, in which pheasant carcasses were eviscerated and then stored at $7{ }^{\circ} \mathrm{C}$, that more pronounced changes in biogenic amine concentrations after 7 days of storage occur in the thigh muscle, and after 14 days of storage in the breast muscle. Changes in breast muscle concentration in chickens stored at $4{ }^{\circ} \mathrm{C}$ were reported in the study conducted by Balamatsia et al. (2006). In their study, the highest increases in concentrations of the monitored biogenic amines were observed in the second week of storage. In agreement with the results of our study, Standarová et al. (2012) described an increase in biogenic amine concentrations in the thigh muscle of uneviscerated pheasants during the second week of storage at refrigeration temperatures $\left(0-2{ }^{\circ} \mathrm{C}\right)$. Although a modest increase in breast muscle concentrations was first observed during storage week one, a more prominent increase did not occur, similarly as in our study, before storage week three. Different results were found when the intensity of biogenic amine formation was compared between breast and thigh muscles of pheasants during the storage period. The results of our study indicate that changes in biogenic amine concentrations in the thigh muscle are much more pronounced than those in the breast muscle throughout the storage period. At the end of the storage period, higher concentrations were detected in the thigh muscle. Standarová et al. (2012) reported more rapid initial increases in biogenic amine concentrations in the thigh muscle than in the breast muscle. From the end of storage week two onwards, however, biogenic amine concentrations in the thigh muscle remained unchanged. At the end of the storage period, they found higher concentrations of biogenic amines in the breast muscle than in the thigh muscle. Similar results were reported by Silva and Glória (2002) who found in their study with poultry after 15 days of storage at $4{ }^{\circ} \mathrm{C}$ higher biogenic amine concentrations in the breast muscle than in the thigh muscle. The above results indicate that the pheasant muscle exhibits certain differences from the chicken muscle. In terms of hygiene, higher risks seem to be posed by the thigh muscle. 
The finding contrary to the results of Standarová et al. (2012) could be explained by the different handling of pheasants after they were killed. The opening made for the purpose of removing internal organs from the body cavity in our study may have been a predisposition factor for secondary contamination from the external environment, which subsequently spread mainly to the thigh muscle area.

In our experiment we also found that the highest concentration increases in the breast muscle of eviscerated pheasants stored at $7{ }^{\circ} \mathrm{C}$ occurred in cadaverine and tyramine. In the thigh muscle, the list of biogenic amines exhibiting marked increases in concentration included beside cadaverine and tyramine, also putrescine. An increase in tyramine and cadaverine concentrations in the breast muscle of chickens stored at $4{ }^{\circ} \mathrm{C}$ was related to the spoilage of meat (Vinci and Antonelli 2002). The largest increases of concentration in the breast muscle of chickens stored at $4{ }^{\circ} \mathrm{C}$ were reported in cadaverine, with putrescine and histamine being identified as the other two biogenic amines exhibiting the largest changes in concentration (Balamatsia et al. 2006). During chicken muscle storage at $4{ }^{\circ} \mathrm{C}$, Silvia and Glória (2002) found the largest changes of concentration in putrescine, cadaverine, tyramine and histamine.

Based on the changes in concentrations of biogenic amines during storage, we can identify cadaverine and tyramine, and possibly putrescine in the thigh muscle as the most important indicators of deterioration in hygienic quality. In contrast to the chicken muscle, histamine in the muscle tissue of eviscerated pheasant stored at $7{ }^{\circ} \mathrm{C}$ does not show any major changes in concentration during storage and, consequently, has only limited informative value. In the case of spermidine and spermine, initial concentrations were already high in our study (breast muscle spermine below $60 \mathrm{mg} / \mathrm{kg}$, thigh muscle spermine below $40 \mathrm{mg} / \mathrm{kg}$; spermidine below $2.5 \mathrm{mg} / \mathrm{kg}$ in both types of muscle). The biogenic amine concentrations found are in agreement with the findings of Kalac and Krausová (2005) who determined spermine concentrations to be between 20-60 $\mathrm{mg} / \mathrm{kg}$ immediately after the animal was sacrificed, and said that spermidine concentrations in meat only rarely exceeded the $10 \mathrm{mg} / \mathrm{kg}$ limit. Elevated concentrations of those two biogenic amines at the very beginning of storage or immediately after the animal was sacrificed are described by a number of other authors in their studies (HernándezJover et al. 1997; Silva and Glória 2002; Vinci and Antonelli 2002; Standarová et al. 2012). The frequent finding of high concentrations of these biogenic amines in the muscle of various animal species is explained by their natural presence in fresh meat, therefore they are not considered indicators of meat spoilage (Hernández-Jover et al. 1997).

\section{Acknowledgement}

This study was supported by the project IGA 93/2011/FVHE.

\section{References}

Balamatsia CC, Paleologos EK, Kontominas MG, Sayvaidis IN 2006: Correlation between microbial flora, sensory changes and biogenic amines formation in fresh chicken meat stored aerobically or under modified atmosphere packing at $4{ }^{\circ} \mathrm{C}$ : possible role of biogenic amines as spoilage indicators. A van Leeuw $\mathrm{J}$ Microbiol 89: 9-17

El-Ghareeb WR, Smulders FJR, Morshdy AMA, Winkelmayer R, Paulsen P 2009: Microbiological condition and shelf life of meat from hunted game birds. Eur J Wildl Res 55: 317-323

Hernández-Jover T, Izquierdo-Pulido M, Veciana-Nogués MT, Mariné-Font A, Vidal-Carou MC 1997: Biogenic amine and polyamine contents in meat and meat products. J Agric Food Chem 45: 2098-2102

Hofbauer P, Smulders FJM, Vodnansky M, Paulsen P, El-Ghareeb WR 2010: A note on meat quality traits of pheasant (Phasianus colchicus). Eur J Wildl Res 56: 809-813

Kalač P, Krausová P 2005: A review of dietary polyamines: formation, implications for growth and health and occurence in foods. Food Chem 90: 219-230

Naila A, Flint S, Fletcher G, Bremer P, Meerdink G 2010: Control of biogenic amines in food-existing and emerging approaches. J Food Sci 75: 139-150 
Paulsen P, Nagy J, Popelka P, Ledecký V, Marcinčák S, Pipová M, Smudlers FJM, Hofbauer P, Lazar P, Dicakova Z 2008: Influence of storage conditions and shotshell wounding on the hygienic condition of hunted, uneviscerated pheasant (Phasianus colchicus). Poultry Sci 87: 191-195

Pichner R, Rodel W, Gareis M 2000: Characterization of pork freshness. Fleischwirtschaft 80: 135-139

Santos MHS 1996: Biogenic amines: their importance in foods. Int J Food Microbiol 29: 213-231

Shalaby AR 1996: Significance of biogenic amines to food safety and human health. Food Res Int 29: 675-690

Silva CMG, Glória BA 2002: Bioactive amines in chicken breast and thigh after slaughter and during storage at $4 \pm 1{ }^{\circ} \mathrm{C}$ and chicken-based meat products. Food Chem 78: 241-248

Standarová E, Vorlová L, Gallas L 2012: Distribution of biogenic amines and polyamines in the pheasant meat. Maso 1: 51-54

Vinci G, Antonelli ML 2002: Biogenic amines: quality index of fresheness in red and white meat. Food Control 13: $519-524$

Winkelmayer R., Lebersorger P, Hans-Friedemann Z 2004: Wildbret-Hygiene: Das Buch zur WildfleischVerordnung. Zentralle Osterr. Landesjagdverbände, Wien, 83 p.

Yano Y, Kataho N, Watanabe M, Nakamura T 1995: Changes in the concentration of biogenic amines and application of tyramine sensor during storage of beef. Food Chem 54: 155-159 